http://jmscr.igmpublication.org/home/

ISSN (e)-2347-176x ISSN (p) 2455-0450

crossref DOI: https://dx.doi.org/10.18535/jmscr/v7i10.124

Journal Of Medical Science And Clinical Research

IGM Publication

An Official Publication of IGM Publication

\title{
A Case of Dyskeratosis Congenita with Early Onset Bone Marrow Failure: A Rare Case Report
}

Authors

Dr Sunil Kumar Agarwalla1, Dr Aparna B Raj ${ }^{2}$

${ }^{1}$ Associate Professor, MKCG MCH, Berhampur, Odisha

${ }^{2} J R 3$, MKCG MCH, Berhampur, Odisha

\begin{abstract}
Dyskeratosis Congenita is a rare hereditary disorder characterized by a triad of nail dystrophy, leukoplakia and abnormal skin pigmentation. Other presentations include BM failure, predisposition to malignancy, and fatal pulmonary disease. BM failure is the most important cause of morbidity and mortality and here, we report a case of 2 year old Female child with Dyskeratosis congenita complicated with pancytopenia and neutropenic fever.

Keywords: Dyskeratosis congenital, BM failure, inherited pancytopenia, dystrophic nails, skin pigmentation.
\end{abstract}

\section{Introduction}

First described in 1906, also known as ZinsserEngman-Cole Syndrome, Dyskeratosis Congenita is characterized by a triad of skin hyperpigmentation, nail dystrophy and mucosal leukoplakia which is seen in $89 \%, 80 \%$ and $45 \%$ patients respectively. ${ }^{(1)}$ It is a hereditary disorder with genetic heterogeneity and the most common pattern of inheritance is $\mathrm{X}$-linked recessive. BM failure occurs in $75 \%$ of patients with $\mathrm{X}$-linked recessive form. ${ }^{(2)}$ Because of its rarity, the case is reported from South Odisha.

\section{Case Report}

2 year old $\mathrm{MCH}$ presented with fever on and off since past 6 months, that got aggravated for past 3 days. There was no H/o rash/cough/. breathlessness/jaundice/seizures/BT. Born as a $3^{\text {rd }}$ order child out of $3^{\text {rd }}$ degree consanguineous marriage, through vaginal delivery with a $\mathrm{BW} ; 2.5$ $\mathrm{kg}$, he had uneventful AN, natal and post natal history. But developmentally, parents reported him to be having motor delay. The family history is uneventful with 2 elder girl siblings doing well. On examination, the vitals were stable, anthropometry revealed microcephaly and short stature in a child who was severely pale with no icterus/cyanosis/clubbing/lymphadenopathy/edem a. The skin was hyperpigmented esp over hands, with dystrophic nails and there was mucosal plaques over tongue,and inner side of cheek. There was no bleeding spots or other congenital anomalies. Systemic examination revealed no abnormality. CBC showed pancytopenia with TLC - 3300 cells/cu.mm with ANC - 480 cells/cu.mm, $\mathrm{Hb}-6.2$ gm\% with a normocytic normochromic picture and Plt- 3000 cells/cu.mm. Retic count was not proportionately elevated, at $1.5 \%$, sickling was negative and RFT,LFT was normal. HPLC showed elevated $\mathrm{HbF}-12 \%$. Bone 
marrow examination revealed suppression of all linaeges, suggestive of hypoplastic anemia. Combining with the mucocutaneous findings, a diagnosis of Dyskeratosis Congenita was made. Genetic studies couldn't be done owing to the poor resource set up and low economic status of the patient. Patient managed conservatively.

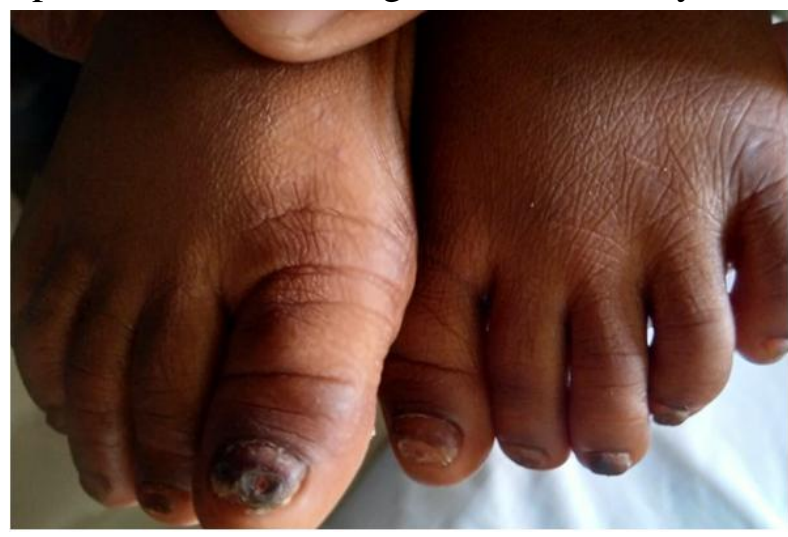

Fig 1 Showing the dystrophic nails in toes

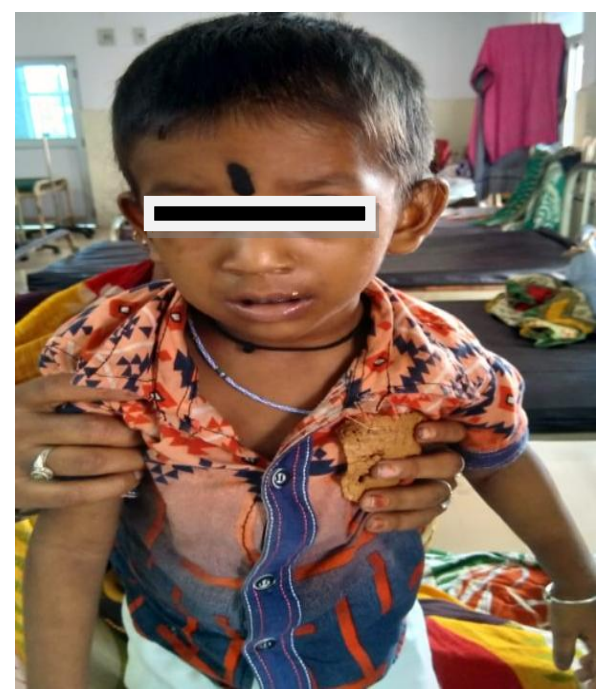

Fig 2 Shows the patient with DC, also showing microcephaly.

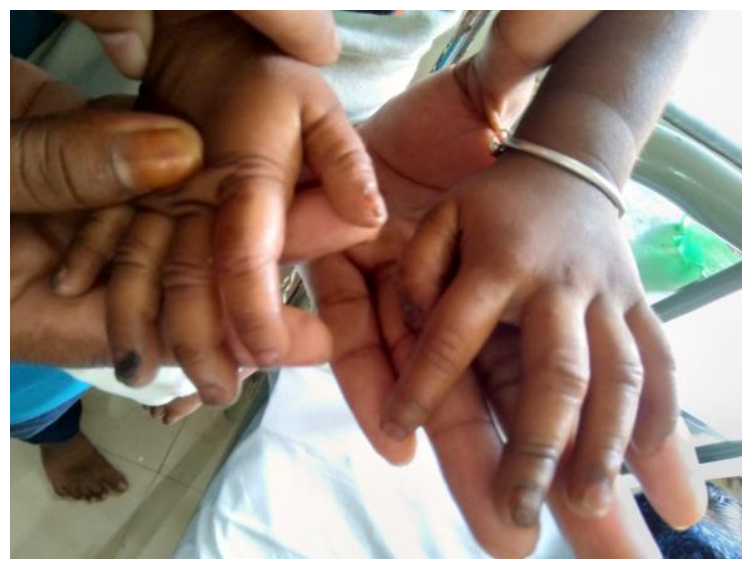

Fig 3 Showing the dystrophic nails in hands

\section{Discussion}

Aplastic anemia in children, is usually due to acquired causes as in adults, but marrow failure during first 3 years of life is relatively uncommon and one has to keep in mind the D.D like congenital infections like TORCH, IEM, and inherited BM failure syndromes like Fanconianemia, DC, Diamond Schwachman syndrome, etc ${ }^{(3)}$.

Dyskeratosis Congenita is a constitutional pancytopenia syndrome, characterized by a triad of abnormal skin pigmentation, nail dystrophy and oral leukoplakia. The leading cause of death is BM failure, that will develop in up to $85 \%$ of cases and is responsible for $80 \%$ of observed mortality $^{(4)}$. The prevalence of classic DC is approximately $1 / 1000000$ individuals and there has only been around 200 cases reported in literature. ${ }^{(5)}$ the skin pigmentation and nail changes usually appear first in $1^{\text {st }}$ decade and BM failure in the $2^{\text {nd }}$ decade $^{(6)}$. Our patient had early onset BM failure.

The diagnosis can be easily established by the clinical triad. Genetic studies show that it's a disease of telomere defect and upto around 90 mutations has been identified ${ }^{(7)}$. The most common pattern of inheritance is $\mathrm{X}$ linked recessive.

Treatment is supportive, and definitive treatment being Hematopoeitic Stem Cell Transplantation. This represent a big challenge in the management of the above said patient because of the non availability of services. It has to be noted that pulmonary and vascular lesions do not respond to HSCT, and hence the cure rate is $50 \%$ only. ${ }^{(8)}$

\section{Conclusion}

DC is a disease of Imarked genetic and clinical heterogeneity. We are reporting this case due to its extreme rarity and early onset type of BM failure and we believe that this would add to the fund of existing knowledge and research on this rare disease. 


\section{References}

1. Dokal I. Dyskeratosis congenital in all its forms. Br J Haematology. 2000; 110(4); 768-779

2. Alter BP. Inherited BM failure syndromes. In: Nathan DG, Ookin SH, Ginsburg D, Look AT et al. Nathan and Oski's hematology of infancy and childhood. Philadelphia; 2003.

3. BP Alter, NGiri et al," Cancer in Dyskeratosis Congenita", Blood, vol 113, no 26, 6549-6557,2009

4. Marimarsaez-De-Ocariz et al. Dyskeratosis congenita, neurocutaneous disorders, phakomatoses, and hematoneoplastic syndrome. 2008.pp 661-668

5. Walne AJ, Dokal I. Advances in understanding of Dyskeratosis Congenita. Br J Haematology. 2009:145(2); 164-172.

6. SA Savage, BP Alter et al, Dyskeratosis Congenita, Hematology/ Oncology clinics of North America, vol.23,no.2, pp215231,2009.

7. Nelson Text book of paediatrics, $20^{\text {th }}$ edn, vol 2 